\title{
Transfusion Support
}

\author{
Hubert Schrezenmeier, Sixten Körper, \\ Britta Höchsmann, and Christof Weinstock
}

\subsection{General Aspects}

Transfusions are an essential part of supportive care in the context of HSCT. RBC and platelet concentrates (PCs) are the main blood products transfused in the peri-transplant period. Many recommendations in this chapter are based on evidence from studies including a broad variety of diseases. Only a few studies addressed transfusion strategy specifically in patients undergoing HSCT (see review Christou et al. 2016). Many recommendations are derived from patients with cytopenia in non-transplant settings. There are both need and opportunity to address issues regarding transfusion of HSCT patients in clinical trials. So far, there is a paucity of studies on the impact of transfusion on HSCT-specific outcomes.

RBC, PC, and FFP for patients who are candidates for HSCT should be leukocyte-reduced, i.e., should contain $<1 \times 10^{6}$ leukocytes/unit. Leukocyte reduction reduces febrile nonhemolytic transfusion reactions and decreases the

\footnotetext{
H. Schrezenmeier $(\bowtie) \cdot$ S. Körper · B. Höchsmann C. Weinstock Institute of Clinical Transfusion Medicine and Immunogenetics Ulm, German Red Cross Blood Transfusion Service Baden-Württemberg-Hessen and University Hospital Ulm, Ulm, Germany

Institute of Transfusion Medicine, University of Ulm, Ulm, Germany

e-mail: h.schrezenmeier@blutspende.de
}

incidence of alloimmunization to leukocyte antigens and the risk of CMV transmission. Also all cellular blood components (RBC, PC, granulocyte transfusions) must be irradiated (see below).

\subsection{Irradiation for Prevention of Transfusion-Associated GvHD (ta-GvHD)}

Ta-GvHD is a rare complication of transfusion wherein viable donor $\mathrm{T}$ lymphocytes in cellular blood products mount an immune response against the recipient (Kopolovic et al. 2015). Some of the clinical presentations of ta-GvHD resemble that of GvHD (fever, cutaneous eruption, diarrhea, liver function abnormalities). Also many patients develop pancytopenia. Since mortality is high (>90\%), prevention of ta-GvHD is critical (Kopolovic et al. 2015). HSCT recipients are at risk of ta-GvHD and should receive irradiated cellular blood products (Kopolovic et al. 2015). It is recommended that no part of the component receives a dose $<25$ Gy and $>50$ Gy (European Committee (Partial Agreement) on Blood Transfusion (CD-P-TS) 2017). Some pathogen-reduction technologies have been shown to inactivate lymphocytes, and additional gamma-irradiation is not required (Cid 2017).

There is no consensus on the duration of the use of irradiated blood products in HSCT recipients. Standard practice is (1) auto-HSCT, at 
least 2 weeks prior to stem cell collection until at least 3 months after HSCT, and (2) allo-HSCT, at the latest starting with conditioning until at least 6 months after HSCT or until immune reconstitution. However, some centers recommend lifetime use of irradiated products since it is difficult to confirm complete and sustained immunological reconstitution.

\subsection{Prevention of CMV Transmission}

The highest risk of transfusion-transmitted CMV (TT-CMV) remains in CMV-seronegative recipients of matched CMV-negative HSCT (Ljungman 2014). Risk of TT-CMV can be reduced by transfusion of leukocyte-reduced blood products (i.e., $<1$ to $5 \times 10^{6}$ residual leukocytes per unit) or by transfusion of blood components from CMVseronegative donors (Ziemann and Thiele 2017). However, it is unclear whether the "belt and suspender approach," i.e., the use of both leukocytereduced and seronegative products, further reduces the risk of TT-CMV. Donations from newly CMVIgG-positive donors bear the highest risk for transmitting CMV infections (Ziemann and Thiele 2017). Currently no international consensus on risk mitigation for $\mathrm{CMV}$ transmission exists. A recent snapshot of current practice revealed that about half of the countries use either leukocytereduced or seronegative products and the other half use the combination of both (Lieberman et al. 2014). Also, there is no consensus how long CMVseronegative products should be given to transplant recipients: the current practice ranges from 100 days after transplant till lifelong (or until CMV seroconversion) (Lieberman et al. 2014).

\subsection{Red Blood Cell Concentrates (RBCs)}

A restrictive RBC transfusion threshold of 7-8 g/ $\mathrm{dL}$ hemoglobin is recommended for adult patients who are hemodynamically stable. A restrictive RBC transfusion threshold of $8 \mathrm{~g} / \mathrm{dL}$ is recommended for patients with existing cardiovascular disease (Carson et al. 2016). These cutoffs are derived from studies on a broad range of indications. Only one randomized clinical trial is available specifically for patients undergoing HSCT (TRIST trial, NCT01237639). It compared a liberal strategy ( $\mathrm{Hb}$ threshold $<90 \mathrm{~g} / \mathrm{L}$ ) with a restrictive strategy $(\mathrm{Hb}$ threshold $<70 \mathrm{~g} / \mathrm{L}$ ). Health-related quality of life was similar between groups, and no appreciable differences in HSCTassociated outcomes were reported (Tay et al. 2016). The median number of RBC units transfused was lower in the restrictive strategy compared to the liberal strategy group, but this did not reach statistical significance (Tay et al. 2016).

In adult recipients, one unit of $\mathrm{RBC}$ increases the hemoglobin concentration by about $1 \mathrm{~g} / \mathrm{dl}$. In children, the dose should be calculated by the formula:

Volume (mL RBC): Target Hb after transfusion (g/ $\mathrm{dL})$ - pretransfusion $\mathrm{Hb}(\mathrm{g} / \mathrm{dL}) \times 4 \times$ weight $(\mathrm{kg})$

In recent years, several randomized trials showed no evidence that transfusion of fresh $\mathrm{RBC}$ reduced morbidity or mortality compared to standard issue RBCs. Thus, the AABB recommends that patients should receive RBC selected at any point within their licensed dating period (Carson et al. 2016).

Chronic RBC transfusions result in iron overload. Hyperferritinemia and iron overload before HSCT are associated with reduced overall survival and incidence of non-relapse mortality after allo-HSCT. However, a meta-analysis (Armand et al. 2014) and a prospective cohort study suggest that iron overload, as assessed by liver iron content, is not a strong prognostic factor for overall survival in a general adult HSCT population. Thus, ferritin alone is an inadequate surrogate for iron overload in HSCT.

\subsection{Platelet Concentrates (PCs)}

PC should be transfused prophylactically to nonbleeding, nonfebrile patients when platelet counts are $\leq 10 \times 10^{9} / \mathrm{L}$ (Schiffer et al. 2018). Prophylactic platelet transfusions may be administered at higher counts based on clinical judgment (Schiffer 
et al. 2018). Patients with active bleeding, febrile conditions, or active infections should receive prophylactic PC transfusions at a threshold of $20 \times 10^{9} / \mathrm{L}$. Also, in case of specific transplantrelated toxicity which might increase the risk of bleeding (acute GvHD, mucositis, hemorrhagic cystitis, or diffuse alveolar hemorrhage), a threshold of $20 \times 10^{9} / \mathrm{L}$ or even higher, based on careful clinical observation, might be justified.

Two prospective randomized control trials comparing prophylactic versus therapeutic PC transfusion in adult patients ( $\geq 16$ years) suggest that a therapeutic transfusion strategy might be feasible in patients after auto-PBSCT but cannot be easily transferred to other indications (AML, allo-HSCT) for whom special attention to the increased risk of bleeding, in particular, CNS bleeding, is needed (Stanworth et al. 2013; Wandt et al. 2012). The results may not be generalizable to children since a subset analysis of the PLADO trial demonstrated that bleeding rates were significantly increased among children, particularly among those undergoing autologous HSCT (Josephson et al. 2012).

The randomized PLADO trial compared different doses of PC transfusions ("low dose," "medium dose," and "high dose" defined as $1.1 \times 10^{11}, 2.2 \times 10^{11}$, and $4.4 \times 10^{11}$ platelets per $\mathrm{m}^{2}$ BSA) (Slichter et al. 2010). While a strategy of "low-dose" transfusion significantly reduces the overall quantity of platelets transfused, patients required more frequent $\mathrm{PC}$ transfusion events (Slichter et al. 2010). At doses between $1.1 \times 10^{11}$ and $4.4 \times 10^{11}$ platelets $/ \mathrm{m}^{2}$, the number of platelets in the prophylactic transfusions had no effect on the incidence of bleeding.

Both apheresis PC and pooled PC from whole blood donations are safe and effective. Available data suggest equivalence of the products in nonallosensitized recipients (Schrezenmeier and Seifried 2010). A clear advantage of apheresis PCs can only be demonstrated in allosensitized patients with HLA- and/or HPA-antibodies who receive antigen-compatible apheresis PCs.

Some patients experience inadequate increment after PC transfusions, i.e., a corrected count increment (CCI) below $5000 / \mu \mathrm{L}$ at $1 \mathrm{~h}$ after transfusion of fresh, ABO-identical PCs on at least two subsequent transfusions. Refractoriness can be caused by non-immunological factors $(>80 \%)$ or immunological factors $(<20 \%)$ (Fig. 23.1). If platelet refractoriness is suspected and no apparent nonimmune causes can be identified, screening for the presence of HLA-Ab is recommended. If HLA-Ab are present, the patient should receive apheresis PCs from matched donors (Juskewitch et al. 2017; Stanworth et al. 2015): ideally all four antigens (HLA-A, HLA-B) of donor and

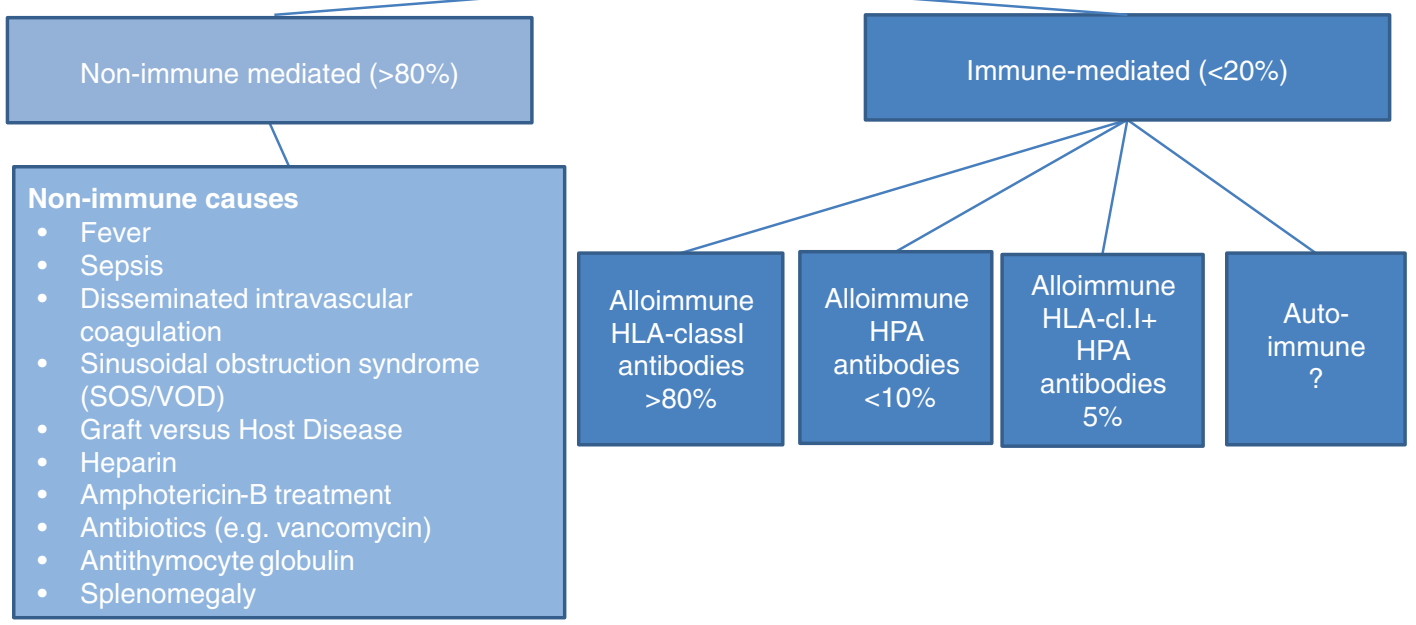

Fig. 23.1 Etiology of platelet transfusion refractoriness (modified according to Pavenski et al. 2012) 
recipient are identical. Also PCs from donors expressing only antigens which are present in the recipient can be used. If PCs from such donors are not available, donors with "permissive" mismatches in HLA-A or HLA-B shall be selected (e.g., based on cross-reactive groups or computer algorithms that determine HLA compatibility at the epitope level). If no better-matched donor is available, antigen-negative platelets, i.e., not expressing the target antigen(s) of the recipients' HLA allo-Ab, can be transfused. Screening for antibodies against human platelet antigens (HPA) should be performed if refractoriness persists also after transfusion of HLA-matched PCs and nonimmune causes are unlikely. Approaches for patients without compatible platelet donors are autologous cryopreserved platelets (e.g., collected in remission prior to allogeneic HSCT), IS (e.g., rituximab), and high-dose IVIg and plasmapheresis.

\subsection{Immunohematological Consequences of ABO- Mismatched Transplantation}

About $40-50 \%$ of allo-HSCT are ABO mismatched. While transplantation across the ABO barrier is possible, immunohematological problems have to be taken into account. There is a risk that $\mathrm{ABO}$ incompatibility between donor and recipient causes hemolytic transfusion reactions. In case of major $\mathrm{ABO}$ mismatch and a recipient anti-donor isoagglutinin titer $\geq 1: 32$, the red cell contamination in PBSC graft should be kept $<20 \mathrm{~mL}$, and RBC depletion of BM grafts must be performed. If recipient anti-donor isoagglutinin titers are low $(\leq 1: 16)$, no manipulation of the PBSC graft is required, and RBC depletion of a $\mathrm{BM}$ graft might be considered in this situation but is not mandatory. In case of minor ABO incompatibility and a high donor anti-recipient isoagglutinin titer $(\geq 1: 256)$, plasma depletion of both PBSC and BM grafts should be performed. If the donor anti-recipient isoagglutinin titer is low ( $\leq 1: 128)$, no manipulation of the PBSC graft is required, and plasma depletion of a BM graft might be considered but is not mandatory. In case of bidirectional $\mathrm{ABO}$ incompatibility and high titers of anti-recipient isoagglutinins, both RBC and plasma depletion is required.

Delayed hemolysis can occur in minor ABOmismatched HSCT, in particular after RIC, due to hemolysis of remaining recipient red cells by isoagglutinins produced by donor B lymphocytes.

Major or bidirectional ABO-incompatible HSCT can cause pure red cell aplasia (PRCA), delayed engraftment, and increased RBC transfusion requirement. The risk is higher if a group $\mathrm{O}$ recipient with high-titer anti-A isoagglutinins receives a group A graft. If no spontaneous remission of PRCA occurs and anti-donor isoagglutinins persist, various treatments to remove isoagglutinins, to reduce their production, or to stimulate erythropoiesis can be used (see review Worel 2016).

\subsection{Transfusion in ABO- or RhD-Incompatible HSCT}

The change of blood group and the persistence of recipient isoagglutinins require a special approach for transfusion support in ABOincompatible HSCT considering several aspects: isoagglutinins might target engrafting progenitors and transfused platelets to which variable amounts of $\mathrm{ABO}$ antigens can be bound. $\mathrm{ABO}$ blood group antigens are expressed in many nonhematopoietic tissues which continue to express the recipients' $\mathrm{ABO}$ antigens also after engraftment. ABO antigens can be secreted into body fluids. If possible, exposure of HSC recipients to isoagglutinins should be avoided. RBCs which are ABO compatible with both HSC donor and recipient are mandatory. Plasma and PCs which are compatible with both the donor and the recipient should be preferred. Table 23.1 summarizes the recommendation for $\mathrm{ABO}$ preference of transfusions in ABO-incompatible HSCT.

For PCs, some choices of blood groups might not always be available. To reduce the risk of adverse events due to isoagglutinins, apheresis $\mathrm{PC}$ donors with high-titer ABO antibodies should be excluded. However, a preferred strategy is the use of plasma-reduced PC (both for apheresis PC and pooled PC from whole blood donations). These are suspended in platelet additive solution with only about $30 \%$ plasma volume remaining. 
Table 23.1 RBC, platelet, and plasma transfusion support for patients undergoing ABO-incompatible HSCT

\begin{tabular}{|c|c|c|c|c|c|c|c|c|}
\hline & \multirow{3}{*}{$\begin{array}{l}\text { Phase } \mathrm{I}^{\mathrm{c}} \\
\text { All } \\
\text { products }\end{array}$} & \multicolumn{5}{|c|}{ Phase II and phase $\mathrm{III}^{\mathrm{c}}$} \\
\hline & & & & \multirow{2}{*}{$\begin{array}{l}\text { RBC } \\
\text { Choice }^{\mathrm{a}}\end{array}$} & \multicolumn{2}{|c|}{ Platelets } & \multicolumn{2}{|l|}{ Plasma } \\
\hline $\begin{array}{l}\mathrm{ABO} \\
\text { incompatibility }\end{array}$ & Recipient & Donor & & & $\begin{array}{l}\text { First } \\
\text { choice }\end{array}$ & $\begin{array}{l}\text { Second } \\
\text { choice }^{\mathrm{a}}\end{array}$ & $\begin{array}{l}\text { First } \\
\text { choice }\end{array}$ & $\begin{array}{l}\text { Second } \\
\text { choice }\end{array}$ \\
\hline \multirow[t]{5}{*}{ Major } & $\mathrm{O}$ & A & Recipient & $\mathrm{O}$ & A & $\mathrm{AB}, \mathrm{B}, \mathrm{O}$ & A & $\mathrm{AB}$ \\
\hline & $\mathrm{O}$ & B & Recipient & $\mathrm{O}$ & B & $\mathrm{AB}, \mathrm{A}, \mathrm{O}$ & B & $\mathrm{AB}$ \\
\hline & $\mathrm{O}$ & $\mathrm{AB}$ & Recipient & $\mathrm{O}$ & $\mathrm{AB}$ & $\mathrm{A}, \mathrm{B}, \mathrm{O}$ & $\mathrm{AB}$ & - \\
\hline & A & $\mathrm{AB}$ & Recipient & $\mathrm{A}, \mathrm{O}$ & $\mathrm{AB}$ & $\mathrm{A}, \mathrm{B}, \mathrm{O}$ & $\mathrm{AB}$ & - \\
\hline & B & $\mathrm{AB}$ & Recipient & $\mathrm{B}, \mathrm{O}$ & $\mathrm{AB}$ & $\mathrm{B}, \mathrm{A}, \mathrm{O}$ & $\mathrm{AB}$ & - \\
\hline \multirow[t]{5}{*}{ Minor } & A & $\mathrm{O}$ & Recipient & $\mathrm{O}$ & $\mathrm{A}^{\mathrm{b}}$ & $\mathrm{AB}, \mathrm{B}, \mathrm{O}$ & A & $\mathrm{AB}$ \\
\hline & B & $\mathrm{O}$ & Recipient & $\mathrm{O}$ & $\mathrm{B}^{\mathrm{b}}$ & $\mathrm{AB}, \mathrm{A}, \mathrm{O}$ & B & $\mathrm{AB}$ \\
\hline & $\mathrm{AB}$ & $\mathrm{O}$ & Recipient & $\mathrm{O}$ & $\mathrm{AB}^{\mathrm{b}}$ & $\mathrm{A}, \mathrm{B}, \mathrm{O}$ & $\mathrm{AB}$ & - \\
\hline & $\mathrm{AB}$ & A & Recipient & $\mathrm{A}, \mathrm{O}$ & $\mathrm{AB}^{\mathrm{b}}$ & $\mathrm{A}, \mathrm{B}, \mathrm{O}$ & $\mathrm{AB}$ & - \\
\hline & $\mathrm{AB}$ & B & Recipient & $\mathrm{B}, \mathrm{O}$ & $\mathrm{AB}^{\mathrm{b}}$ & $\mathrm{B}, \mathrm{A}, \mathrm{O}$ & $\mathrm{AB}$ & - \\
\hline \multirow[t]{2}{*}{ Bidirectional } & A & B & Recipient & $\mathrm{O}$ & $\mathrm{AB}$ & $\mathrm{B}, \mathrm{A}, \mathrm{O}$ & $\mathrm{AB}$ & - \\
\hline & B & A & Recipient & $\mathrm{O}$ & $\mathrm{AB}$ & $\mathrm{A}, \mathrm{B}, \mathrm{O}$ & $\mathrm{AB}$ & - \\
\hline
\end{tabular}

- not applicable

${ }^{\mathrm{a}}$ Choices are listed in the order of preference

${ }^{b}$ For practical reasons, the use of donor type platelets might be defined as first choice, in phase III, i.e., after complete engraftment

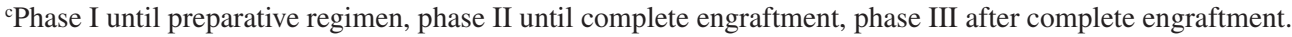

HSC recipients should receive $\mathrm{RhD}$-negative $\mathrm{RBC}$ and also RhD-negative PC except when both HSC donor and recipient are $\mathrm{RhD}$-positive. If the HSC donor is $\mathrm{RhD}$-positive and the recipient is RhD-negative, platelet transfusion can be switched to $\mathrm{RhD}$-positive products after erythroid engraftment, i.e., appearance of $\mathrm{RhD}$ positive red cells.

Whenever possible, RBC should be compatible both with HSCT donor and recipient for $\mathrm{CcEe}$ antigens. If $\mathrm{Rh}$ antigens of HSCT donor and recipient differ in a way that compatibility with both is not possible (e.g., recipient CCD.ee, donor ccD.EE), then RBC compatible with the recipient shall be chosen in the period until engraftment. After the appearance of donorderived red cells, RBC supply should switch to compatibility with the graft. Patients should receive K-negative $\mathrm{RBC}$ except when both recipient and donor are $\mathrm{K}$ positive.

\subsection{Granulocyte Concentrates}

In life-threatening non-viral infections during neutropenia, the use of irradiated granulocyte transfusions should be considered. Response and survival after granulocyte transfusion cor- relate strongly with hematopoietic recovery. Thus, granulocyte transfusions may mainly bridge the gap between specific treatment and neutrophil recovery. Granulocyte transfusions can help to control active fungal infections in a very high-risk population of patients who otherwise are denied by transplant program. A retrospective study suggested that granulocyte transfusion might maintain the mucosal integrity and thus reduces bacterial translocation and triggers for GvHD. In the randomized RING trial, success rates for granulocyte and control arms did not differ within any infection type. The overall success rates for the control and granulocyte transfusion group were $41 \%$ and $49 \%$ (n.s.) (Price 2015). However, patients who received high dose $\left(\geq 0.6 \times 10^{9}\right.$ granulocytes $/ \mathrm{kg}$ per transfusion) fared better than patients who received lower doses. The collection center should ensure to provide a high-dose concentrate by appropriate donor selection, pre-collection stimulation, and apheresis techniques. The optimal number of granulocyte transfusions is unclear. Adverse events of granulocyte infusions are fever, chills, pulmonary reactions, and alloimmunization. Studies demonstrated that overall risk of alloimmunizations was low and there 
was no effect of alloimmunization on the primary outcome (survival, microbial response), the occurrence of transfusion reactions, or post transfusion neutrophil increments. Alloimmunization remains a problem because of its negative impact on increments after platelet transfusion and potential increase of graft failure after HSCT. Donor-specific HLA-Ab might be implicated in early graft failure (Spellman et al. 2010). If granulocyte transfusions are used prior to a planned unrelated HSCT, recipients should be monitored for the development of HLA-Ab, and the search algorithm for the UD should take into account donor-specific antibodies. All granulocyte concentrates must be gamma-irradiated and should be obtained from CMVseronegative donors, ideally also confirmed by CMV-PCR to avoid donations in the serological window period.

\section{Key Points}

- Patients undergoing HSCT must be transfused with irradiated blood products (at least 2 weeks prior to stem cell collection in auto- and starting with the conditioning in allo-HSCT)

- A restrictive RBC transfusion threshold of 7-8 $\mathrm{g} / \mathrm{dL}$ hemoglobin is recommended for adult patients who are hemodynamically stable

- RBC must be compatible with both the HSC donor and the recipients

- Platelet concentrates should be transfused to non-bleeding, nonfebrile patients when platelet counts are $\leq 10 \times 10^{9} / \mathrm{L}$

- Prophylactic platelet transfusion remains the standard of care for thrombocytopenic patients undergoing allogeneic HSCT

- RBC must be compatible with both the HSC donor and the recipient

\section{References}

Armand P, Kim HT, Virtanen JM, et al. Iron overload in allogeneic hematopoietic cell transplantation outcome: a meta-analysis. Biol Blood Marrow Transplant. 2014;20:1248-51.

Carson JL, Guyatt G, Heddle NM, et al. Clinical practice guidelines from the AABB: red blood cell transfusion thresholds and storage. JAMA. 2016;316: 2025-35.

Christou G, Iyengar A, Shorr R, et al. Optimal transfusion practices after allogeneic hematopoietic cell transplantation: a systematic scoping review of evidence from randomized controlled trials. Transfusion. 2016;56:2607-14.

Cid J. Prevention of transfusion-associated graft-versushost disease with pathogen-reduced platelets with amotosalen and ultraviolet A light: a review. Vox Sang. 2017;112:607-13.

European Committee (Partial Agreement) on Blood Transfusion (CD-P-TS). Guide to the preparation, use and quality assurance of blood components. 19th. 2017. EDQM.

Josephson CD, Granger S, Assmann SF, et al. Bleeding risks are higher in children versus adults given prophylactic platelet transfusions for treatmentinduced hypoproliferative thrombocytopenia. Blood. 2012;120:748-60.

Juskewitch JE, Norgan AP, De Goey SR, et al. How do I ... manage the platelet transfusion-refractory patient? Transfusion. 2017;57:2828-35.

Kopolovic I, Ostro J, Tsubota H, et al. A systematic review of transfusion-associated graft-versus-host disease. Blood. 2015;126:406-14.

Lieberman L, Devine DV, Reesink HW, et al. Prevention of transfusion-transmitted cytomegalovirus (CMV) infection: standards of care. Vox Sang. 2014; 107:276-311.

Ljungman P. The role of cytomegalovirus serostatus on outcome of hematopoietic stem cell transplantation. Curr Opin Hematol. 2014;21:466-9.

Pavenski K, Freedman J, Semple JW. HLA alloimmunization against platelet transfusions: pathophysiology, significance, prevention and management. Tissue Antigens. 2012;79:237-45.

Price TH, Boeckh M, Harrison RW, et al. Efficacy of transfusion with granulocytes from G-CSF/dexamethasone-treated donors in neutropenic patients with infection. Blood. 2015;126:2153-61.

Schiffer CA, Bohlke K, Delaney M, et al. Platelet transfusion for patients with cancer: American Society of Clinical Oncology clinical practice guideline update. J Clin Oncol. 2018;36:283-99.

Schrezenmeier H, Seifried E. Buffy-coat-derived pooled platelet concentrates and apheresis platelet concentrates: which product type should be preferred? Vox Sang. 2010;99:1-15. 
Slichter SJ, Kaufman RM, Assmann SF, et al. Dose of prophylactic platelet transfusions and prevention of hemorrhage. N Engl J Med. 2010;362:600-13.

Spellman S, Bray R, Rosen-Bronson S, et al. The detection of donor-directed, HLA-specific alloantibodies in recipients of unrelated hematopoietic cell transplantation is predictive of graft failure. Blood. 2010;115:2704-8.

Stanworth SJ, Estcourt LJ, Powter G, et al. A noprophylaxis platelet-transfusion strategy for hematologic cancers. N Engl J Med. 2013;368:1771-80.

Stanworth SJ, Navarrete C, Estcourt L, Marsh J. Platelet refractoriness-practical approaches and ongoing dilemmas in patient management. $\mathrm{Br} \mathrm{J}$ Haematol. 2015; 171:297-305.
Tay J, Allan DS, Chatelein E, et al. Transfusion of red cells in hematopoietic stem cell transplantation (TRIST study): a randomized controlled trial evaluating 2 red cell transfusion thresholds. Blood. 2016;128:1032.

Wandt $\mathrm{H}$, Schaefer-Eckart $\mathrm{K}$, Wendelin $\mathrm{K}$, et al. Therapeutic platelet transfusion versus routine prophylactic transfusion in patients with haematological malignancies: an open-label, multicentre, randomised study. Lancet. 2012;380:1309-16.

Worel N. ABO-mismatched allogeneic hematopoietic stem cell transplantation. Transfus Med Hemother. 2016;43:3-12.

Ziemann M, Thiele T. Transfusion-transmitted CMV infection-current knowledge and future perspectives. Transfus Med. 2017;27:238-48.

Open Access This chapter is licensed under the terms of the Creative Commons Attribution 4.0 International License (http://creativecommons.org/licenses/by/4.0/), which permits use, sharing, adaptation, distribution and reproduction in any medium or format, as long as you give appropriate credit to the original author(s) and the source, provide a link to the Creative Commons license and indicate if changes were made.

The images or other third party material in this chapter are included in the chapter's Creative Commons license, unless indicated otherwise in a credit line to the material. If material is not included in the chapter's Creative Commons license and your intended use is not permitted by statutory regulation or exceeds the permitted use, you will need to obtain permission directly from the copyright holder. 